\title{
Allergic rhinitis in India: an overview
}

\section{Chandrika*}

Department of Otorhinolaryngology, SDM medical college, Dharwad, Karnataka, India

Received: 12 September 2016

Revised: 17 October 2016

Accepted: 07 November 2016

\author{
*Correspondence: \\ Dr. D. Chandrika, \\ E-mail: chandrikad1508@gmail.com
}

Copyright: () the author(s), publisher and licensee Medip Academy. This is an open-access article distributed under the terms of the Creative Commons Attribution Non-Commercial License, which permits unrestricted non-commercial use, distribution, and reproduction in any medium, provided the original work is properly cited.

\begin{abstract}
Prevalence of allergic diseases including asthma, rhinitis, anaphylaxis, food, drug or insect allergy, is rising worldwide affecting about $10-25 \%$ of population being one of the top ten reasons for visit to primary care physicians. Though it often adversely affects the quality of life; in India allergic rhinitis is often regarded as trivial disease and patients fail to attribute the ill health to its symptoms. In study on children with allergic rhinitis nasal symptoms and rhinoconjunctivitis were present and there was consistent rise in its prevalence. Proportion of blockers is higher compared to sneeze runners. Nasal obstruction was the most common symptom and blockers had significantly more sensitization to polyvalent house dust, house dust mites and fungi, whereas sneeze-runners had more sensitization to pollens, asthma was the most common comorbid condition present, In majority of children had one or more comorbidity, allergic rhinitis adversely affected behaviour, work performance and life style of patients.
\end{abstract}

Keywords: Allergic rhinitis, India, Allergic rhinoconjunctivitis, Pollen, Sneeze runners

\section{INTRODUCTION}

The prevalence of allergic diseases including asthma, rhinitis, anaphylaxis, food ,drug or insect allergy, is rising worldwide. ${ }^{\prime}$ Allergic rhinitis is one of most common allergic diseases worldwide, affecting about $10-25 \%$ of population. It is one of the top ten reasons for visit to primary care physicians. ${ }^{2}$

\section{ALLERGIC RHINITIS BURDEN}

The burden of allergic rhinitis is enormous, constituting about $55 \%$ of all allergies. ${ }^{3}$ About $20-30 \%$ of Indian population suffers from at least one allergic diseases. ${ }^{3}$ Reported incidence of allergic rhinitis in India also ranges between $20 \%$ and $30 \%{ }^{4}$ Studies have shown that prevalence of allergic rhinitis has been increasing in India over past few years. According to study of International study of asthma and allergies in childhood (ISSAC) phase 1 (1998), in India nasal symptoms alone were present in $12.5 \%$ children in 6-7 years age group and $18.6 \%$ in $13-$
14 years age group, while allergic rhinoconjunctivitis was observed in $3.3 \%$ and $5.6 \%$ children, respectively as shown in Figure 1.

However in ISSAC phase 3 (2009) study, prevalence of nasal symptoms increased to $12.9 \%$ and $23.6 \%$ in $6-7$ and 13-14 year age groups, respectively, while that of allergic rhinoconjunctivitis increased to 3.9 and $10.4 \%$ respectively as shown in Figure 2.

Similar findings are documented in a recently published study from Mysore. There has been a consistently rising trend of allergic rhinitis in children (6-14 years old) over period of 15 years from 1998 to 2013 as given in Figure 3.

\section{SYMPTOMS OF ALLERGIC RHINITIS}

Allergic rhinitis is often classified as sneeze runners and blockers because of their distinct clinical profile and need of a different treatment approach. In patients who are 
predominantly sneezers and runners, the main symptoms are sneezing, anterior rhinorrhea and itchy nose and eyes. On the other hand, blockers have nasal congestion as predominant symptom, wherein nasal blockage and thick mucus can lead to post nasal drip and breathlessness. ${ }^{2}$ In recent study, Deb and colleagues screened 548 Indian adults with allergic rhinitis and showed that the proportion of blockers is significantly higher compared to sneeze runners as shown in Figure 4. On classifying patients according to ARIA guideline, moderate to severe persistent allergic rhinitis was most common type of allergic rhinitis and was prevalent in nearly one third of patients as given in Figure 5. Similarly, a questionnaire based survey among 2300 school children from Jaipur aged 4-18 years showed nasal obstruction to be the most common symptom. The commonest symptoms of allergic rhinitis are shown in Figure 6. Among the children with allergic rhinitis, $35.6 \%$ experienced intermittent symptoms while $64.3 \%$ had persistent disease. ${ }^{8}$

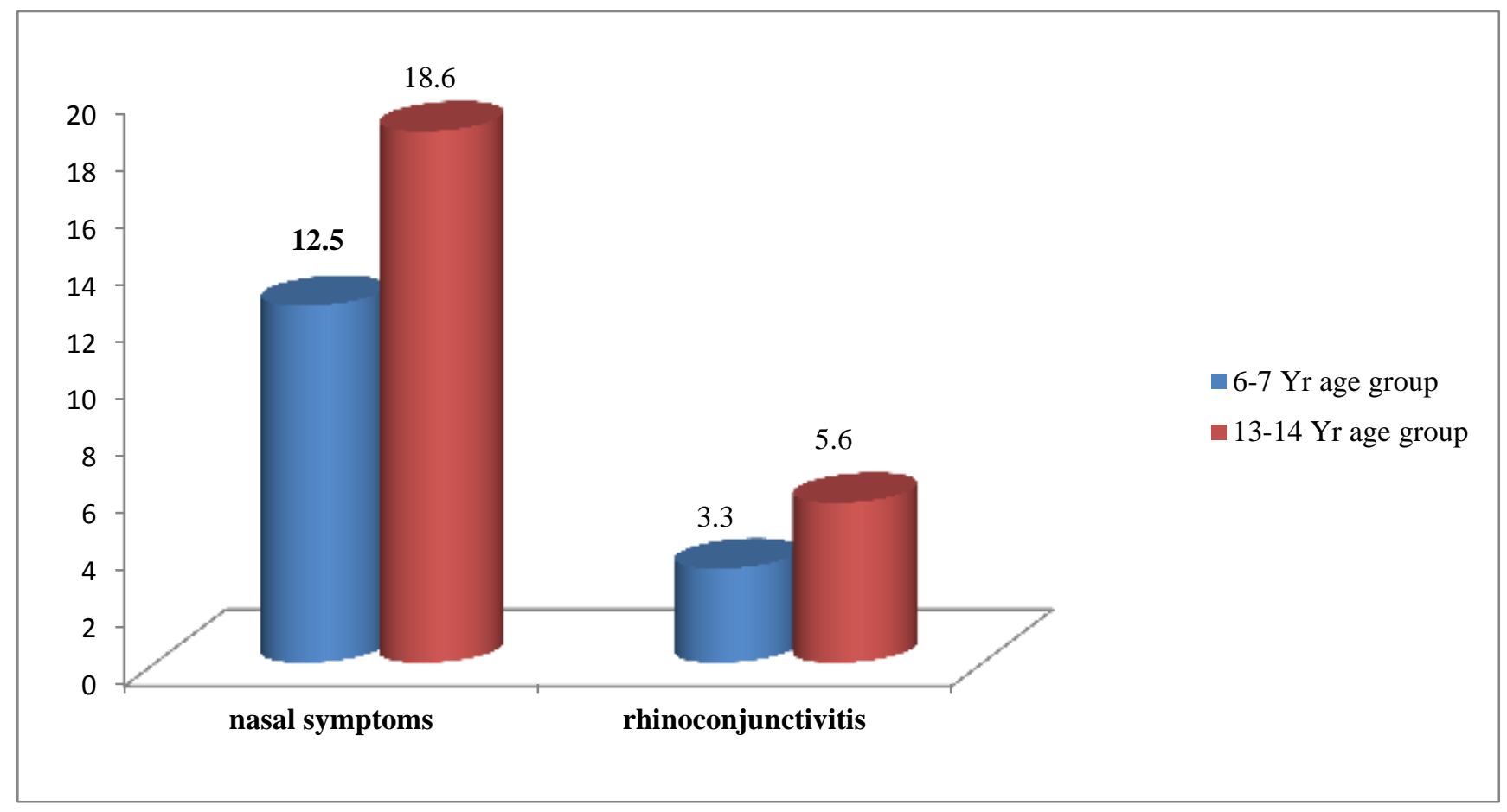

Figure 1: Burden of allergic rhinitis.

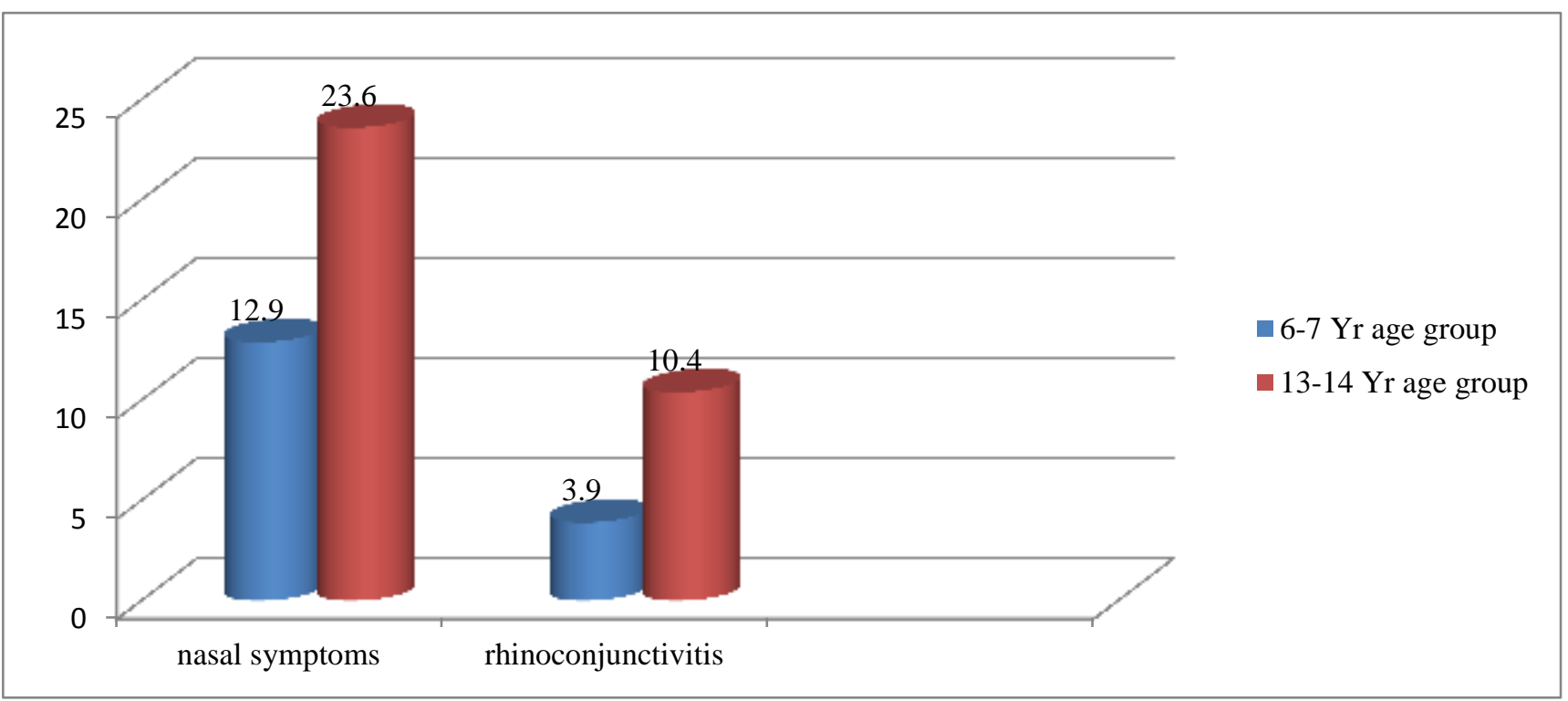

Figure 2: Burden of allergic rhinitis. 


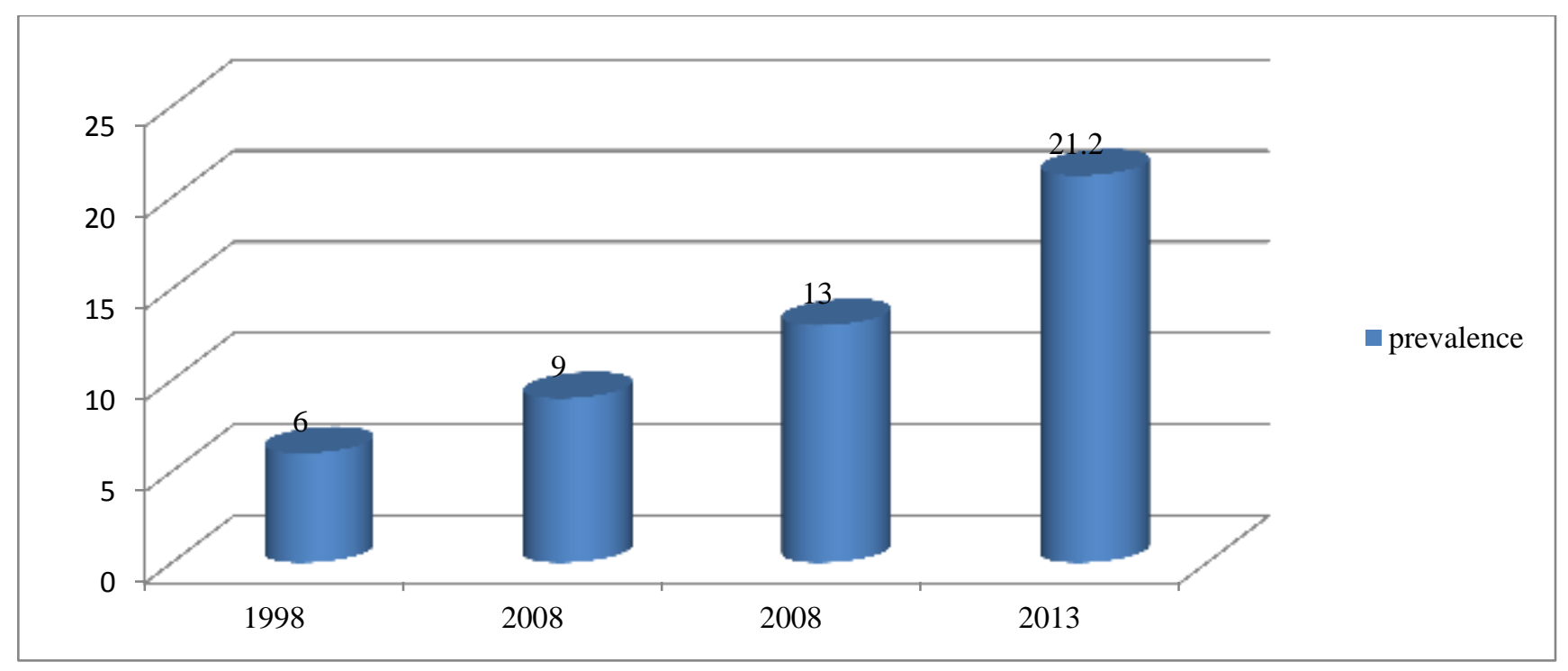

Figure 3: Prevalence of allergic rhinitis.

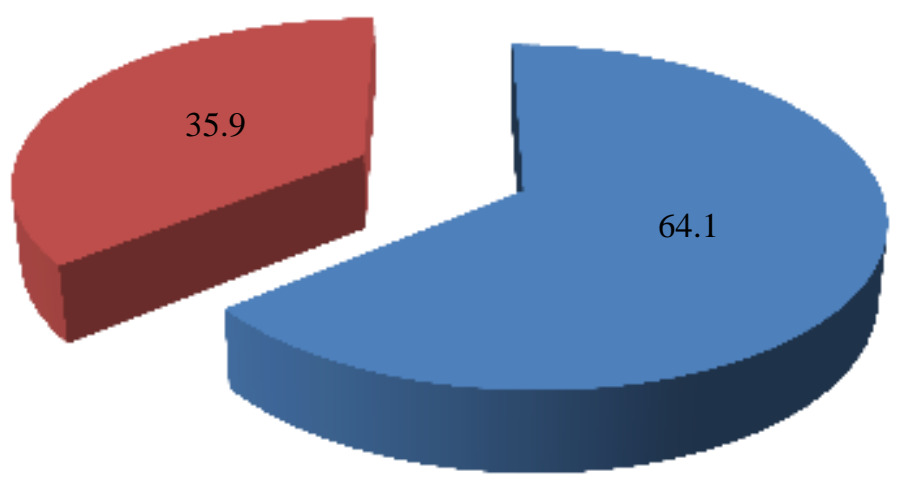

- blockers

$\square$ sneeze runners

Figure 4: Symptom distribution in allergic rhinitis.

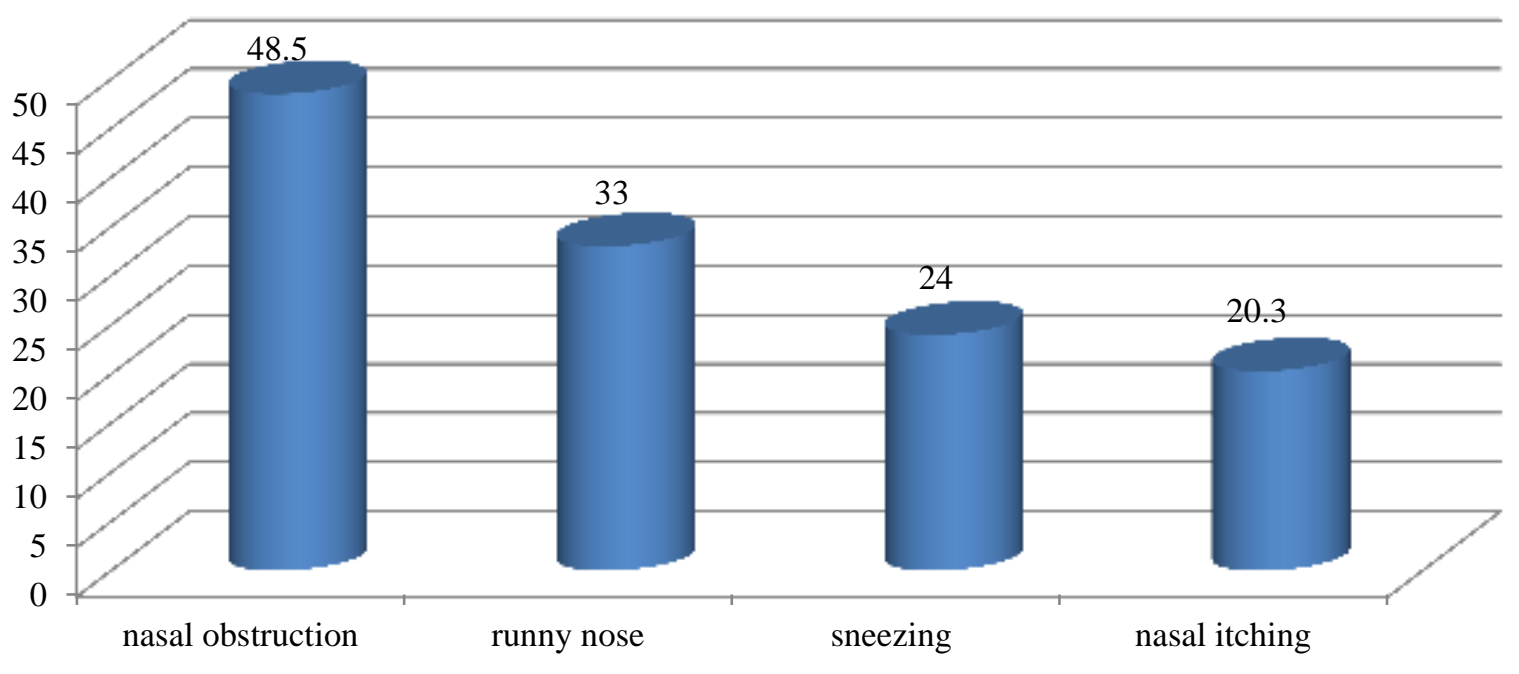

Figure 5: Contribution of symptoms in allergic rhinitis. 


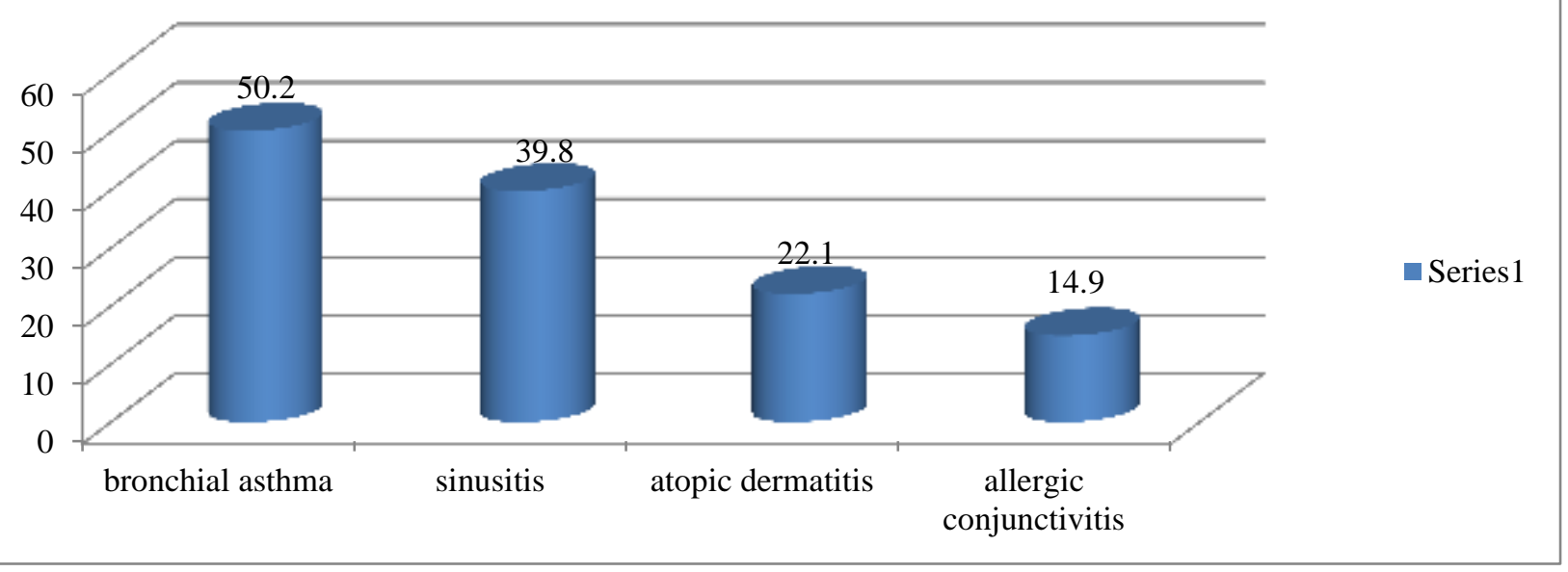

Figure 6: Comorbid conditions of allergic rhinitis.

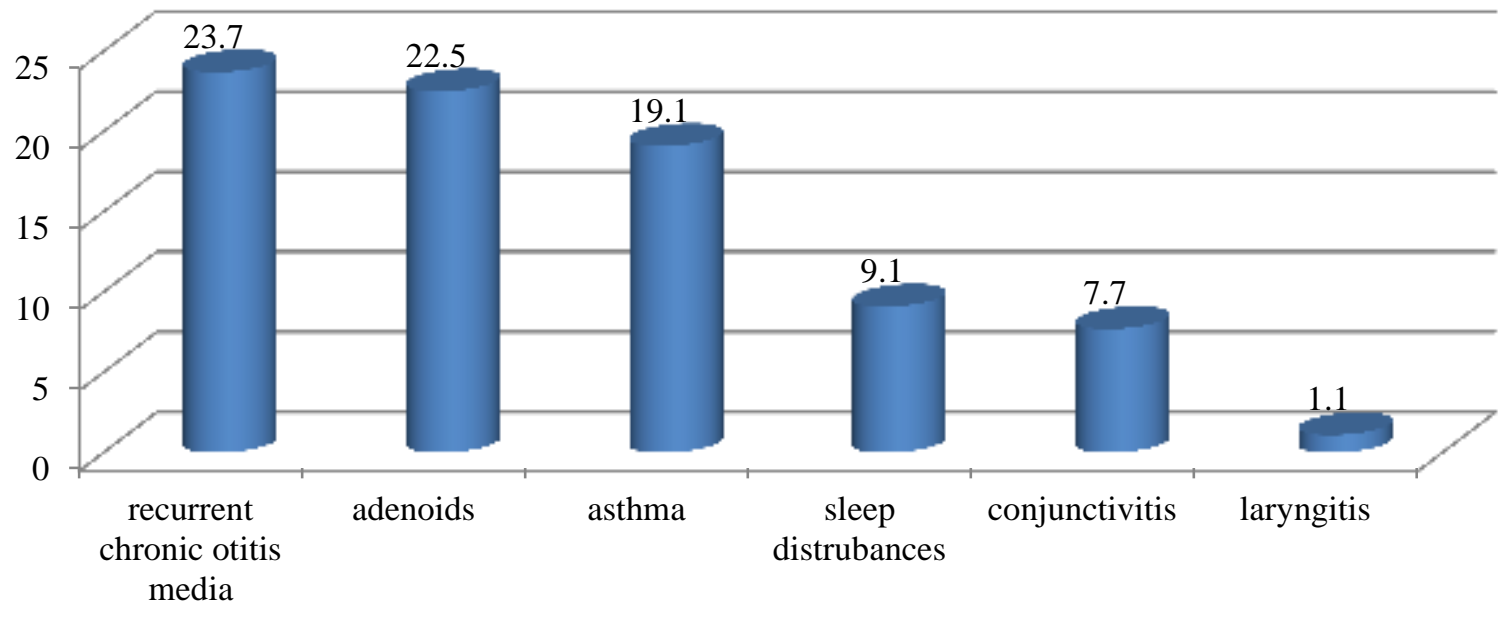

Figure 7: Comorbid conditions of allergic rhinitis.

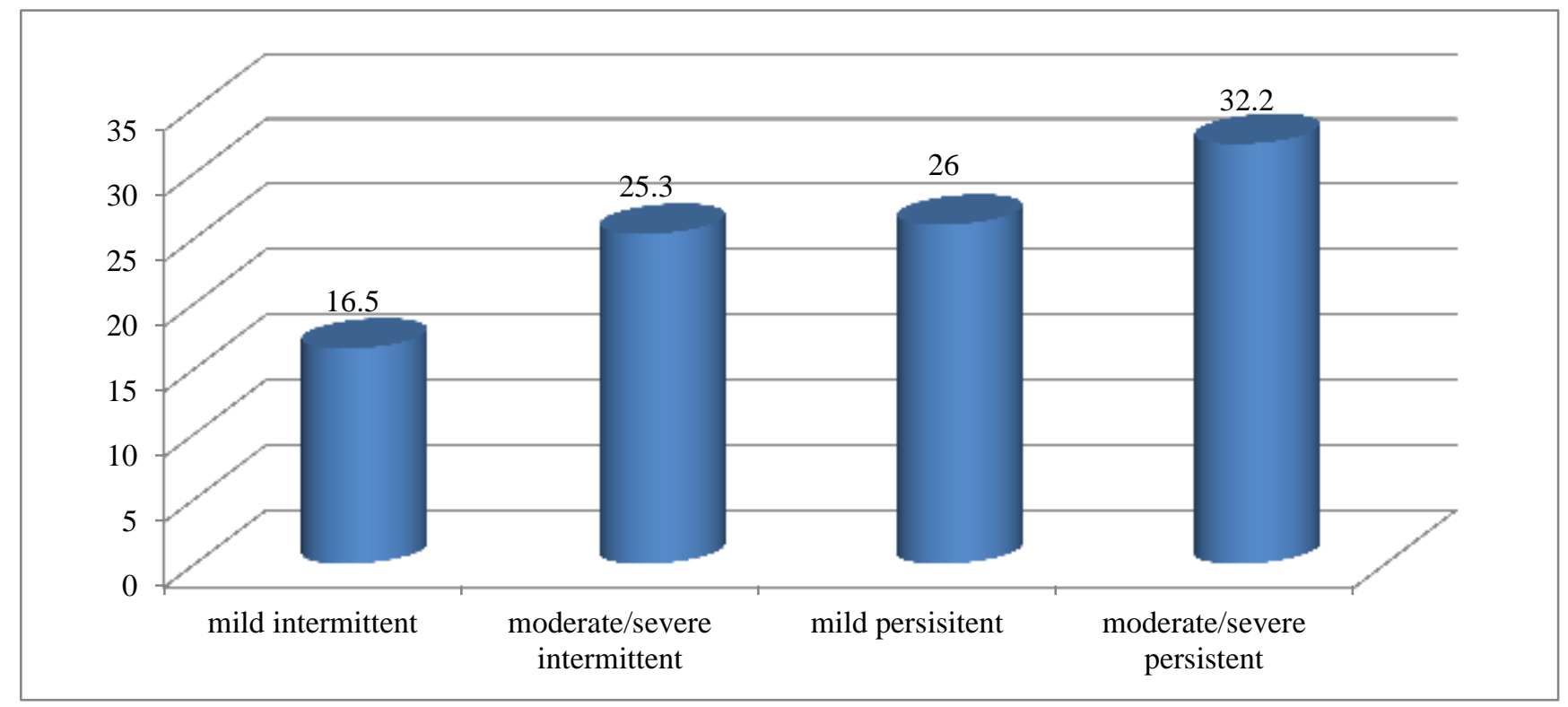

Figure 8: Severity of symptoms in allergic rhinitis. 


\section{COMMON ALLERGENS}

Allergic rhinitis is frequently caused by exposure to perennial or seasonal allergens present in the indoor and outdoor environment, the most common ones being:

Pollens (grass, trees, weeds), house dust mites, pets, molds. ${ }^{9}$ The study by Deb et al showed that blockers had significantly more sensitization to polyvalent house dust, house dust mites and fungi, whereas sneezers-runners had more sensitization to pollens as given in Table $1 .^{2}$

Table 1: Common allergens.

\begin{tabular}{|llll|}
\hline Allergens & $\begin{array}{l}\text { Sneeze } \\
\text { runners }\end{array}$ & $\begin{array}{l}\text { Blockers } \\
\mathrm{n}(\%)\end{array}$ & $\mathrm{n}(\%)$ \\
\hline $\begin{array}{l}\text { Polyvalent } \\
\text { house dust }\end{array}$ & $66(39.8)$ & $159(53.7)$ & 0.006 \\
\hline Pollens & $128(77.1)$ & $71(24.0)$ & $<0.001$ \\
\hline $\begin{array}{l}\text { House dust } \\
\text { mites }\end{array}$ & $27(16.3)$ & $85(28.7)$ & 0.004 \\
\hline Fungi & $22(13.2)$ & $116(39.2)$ & $<0.001$ \\
\hline Danders & $18(10.8)$ & $48(16.2)$ & 0.146 \\
\hline Insects & $27(16.3)$ & $62(20.9)$ & 0.28 \\
\hline Food & $30(18.1)$ & $67(22.6)$ & 0.307 \\
\hline
\end{tabular}

\section{COMMON COMORBIDITIES IN ALLERGIC RHINITIS}

Allergic rhinitis is associated with number of comorbid conditions such as asthma, sinusitis, otitis media, atopic dermatitis and nasal polyps. ${ }^{10}$ In the study by Deb et al asthma was the most common comorbid condition, present in almost half of patients as given in Figure $7 .^{2}$ In children with allergic rhinitis majority of children had one or more comorbidity (58.1\%), whereas $22 \%$ children had 2 or more comorbidities. A total of $41.9 \%$ had no comorbid condition. ${ }^{11}$ The prevalence of different comorbidities is shown in Figure 8.

\section{QUALITY OF LIFE IN ALLERGIC RHINITIS}

Though it often adversely affects the quality of life; in India allergic rhinitis is often regarded as trivial disease and patients fail to attribute the ill health to symptoms of allergic rhinitis. ${ }^{1}$ Allergic rhinitis has negative impact on quality of life. Allergic rhinitis can affect the physical, psychological and social aspects and impact work productivity. A study involving 34 Indian patients with allergic rhinitis showed that allergic rhinitis adversely affected behaviour, work performance and life style of patients. Further allergic rhinitis caused hindrance at work due to repeated blowing of nose and need to rub eyes and nose. ${ }^{12}$

\section{CONCLUSION}

In India $20-30 \%$ of the population suffers from allergic rhinitis and/or other allergic diseases, prevalence being increasing over past many years. Allergic rhinitis patients can be classified as sneeze runners and blockers. The most common symptoms being sneezing, running nose, nasal itching and nasal obstruction. Allergens commonly implicated are pollens, house dust mites, pets and molds. Allergic rhinitis is associated with number of co morbid conditions such as asthma, sinusitis, otitis media, atopic dermatitis, conjunctivitis and nasal polyps. Allergic rhinitis adversely affects quality of life of patient.

Funding: No funding sources

Conflict of interest: None declared

Ethical approval: Not required

\section{REFERENCES}

1. Pawankar R, Canonica GW, Holgate ST, Lockey RF. Allergic diseases as global public health issue.WAO white book on allergy 2011-2012: executive summary. Available at: http//www.world allergy.org/publications/wao_white_book.pdf. Accessed on 24 August 2015.

2. Deb A, Mukherjee S, Saha BK, Sarkar BS, Pal J, Pandy, et al. profile of patients with allergic rhinitis: a clinic based cross sectional study from Kolkata, India. J Clin Diagn Resp. 2014;8(1):67-70.

3. Prasad R, Kumar R. Allergy situation in India: what is being done? Indian $\mathbf{J}$ chest dis allied Sci. 2013;55:7-8.

4. Varshney J, Varshney. Allergic rhinitis: an overview. Indian J otolayngol Head Neck Surg. 2015;67(2):143-9.

5. Shah A, Pawankar R. allergic rhinitis and comorbid asthma: perspective from india- ARIA asia -pacific workshop report. Asian Pac J allergy Immunol. 2009;27(1):71-7.

6. Mir E, Panjabi C, Shah. Impact of allergic rhinitis in school going children. Asia Pac allergy. 2012;2(2):93-100.

7. Sanjana JM, Mahesh PA, Jayaraj BS, Lokesh KS. Changing trends in prevalence of asthma and allergic rhinitis in children in Mysore, South India. ERJ. 2014;44(58):1187.

8. Saini A, Gupta M, Sharma B, Kakkar M, Chaturvedy G, Gupta M. Rhinitis, sinusitis and ocular disease-2085. Prevalence of allergic rhinitis in urban school children, Jaipur city India. World allergy Org J. 2013;6(1):164.

9. Wang DY. Risk factors of allergic rhinitis: genetic or environmental? Ther Clin Risk Manag. 2005;1(2):115-23.

10. Pherwani A, Mankekar G, Chavan K, Periera C, Bansode G. The study of comorbid conditions in adults with allergic rhinitis from Mumbai, Maharashtra, India and their comparison with 
children. Ind J otolryngol Head Neck Surg. 2009;61(1):5-8.

11. Sharma D, Dutta BK, Singh AB. Prevalence of allergic diseases in humid tropical climate of south Assam, India. Global $\mathbf{J}$ immunol allergic dis. 2014;2:1-10.

12. Kolothumveettil J. A study to assess the effictiveness of planned teaching program on knowledge regarding prevention and management of allergic rhinitis among mothers of school children in selected areas of Mangalore, 2010. Available at http: //www.rguhs.ac.in/cdc/onlinecdc/uploads/05 N298_23905.doc. Accessed on 5th August 2015.

Cite this article as: Chandrika D. Allergic rhinitis in India: an overview. Int J Otorhinolaryngol Head Neck Surg 2017;3:1-6. 